\title{
Robust Response of Streamflow Drought to Different Timescales of Meteorological Drought in Xiangjiang River Basin of China
}

\author{
Lin Zhao, ${ }^{1}$ Jianjun $\mathrm{Wu}^{2}$ and Jian Fang ${ }^{1}$ \\ ${ }^{1}$ School of Resource and Environmental Sciences, Wuhan University, Wuhan 430079, China \\ ${ }^{2}$ Academy of Disaster Reduction and Emergency Management, Beijing Normal University, Beijing 100875, China \\ Correspondence should be addressed to Jian Fang; fj20061028@126.com
}

Received 2 June 2015; Accepted 1 October 2015

Academic Editor: Maurits W. Ertsen

Copyright (c) 2016 Lin Zhao et al. This is an open access article distributed under the Creative Commons Attribution License, which permits unrestricted use, distribution, and reproduction in any medium, provided the original work is properly cited.

\begin{abstract}
Meteorological drought can evolve into all aspects of hydrologic system such as soil layer, groundwater, and river discharge, leading to agricultural drought, groundwater drought, and streamflow drought, respectively. How does it propagate? Is there any strong relationship between meteorological drought and others? These issues need further understanding regarding different climate regions. In this paper, monthly SRI and SPEI at different timescales during 1976 and 2005 were utilized to understand how streamflow drought responded to meteorological drought in Xiangjiang river basin, a semihumid basin of Central China. Impressive findings included that strong correlations between SRI and SPEI were found. SPEI of 2-month timescale behaved best when correlating with SRI $(R=0.79)$. Longer timescales of SPEI seemed not to be useful for streamflow drought identification. At seasonal scale, higher correlation coefficients were obtained during dry season, whereas lower coefficients were found in wet season. The maximum $R$ reached up to 0.89 in November at 2-month timescale. Besides, robust response relation between streamflow drought and meteorological drought was also found. The average response rate $\left(R_{r}\right)$ was considerably high $(75.4 \%)$, with the maximum obtained at 2-month timescale $\left(R_{r}=82.9 \%\right)$. Meanwhile, important seasonal difference of response rate has also been pointed out.
\end{abstract}

\section{Introduction}

Drought is a multifaceted phenomenon that occurs across a range of temporal and spatial scales [1], characterized by periods of more than normal water deficit. It is one of the most damaging natural disasters all over the world [2], causing significant damage to different sectors of natural environment, such as vegetation growth $[3,4]$, crop yield [5, 6], water supply [7], desertification [8], and forest fire [9]. Due to global warming, the dry land areas have increased significantly in the past fifty years [10] and widespread severe droughts in the next 30-90 years over many land areas were also simulated by most models [11].

Four basic categories of drought have been identified by Wilhite and Glantz in 1985 [12], which are meteorological drought, agricultural drought, hydrological drought, and socioeconomic drought. Prolonged severe meteorological drought will gradually propagate into different sectors of water resources, such as soil moisture, groundwater, and river discharge, leading to soil drought, groundwater drought, and streamflow drought. The propagation of drought through hydrologic system is complex, which may be affected by underlying conditions such as land cover, vegetation, and topography [13-15]. Understanding of this propagation procedure and how it behaves in different area would not only be helpful for drought monitoring and early warning, but also provide further support in theory and practical implications for making regional drought plans.

A few number of previous studies have reported on the relationship between hydrological drought and meteorological drought. Part of studies have paid attention to the evolution of drought characteristics when it propagated through different hydrologic systems. Hisdal and Tallaksen conducted a study on the comparison between regional characteristics of meteorological drought and hydrological drought in Denmark and found that hydrological droughts were less homogeneous over Denmark, less frequent, and lasted for longer time periods than meteorological drought [16]. Peters et al. 


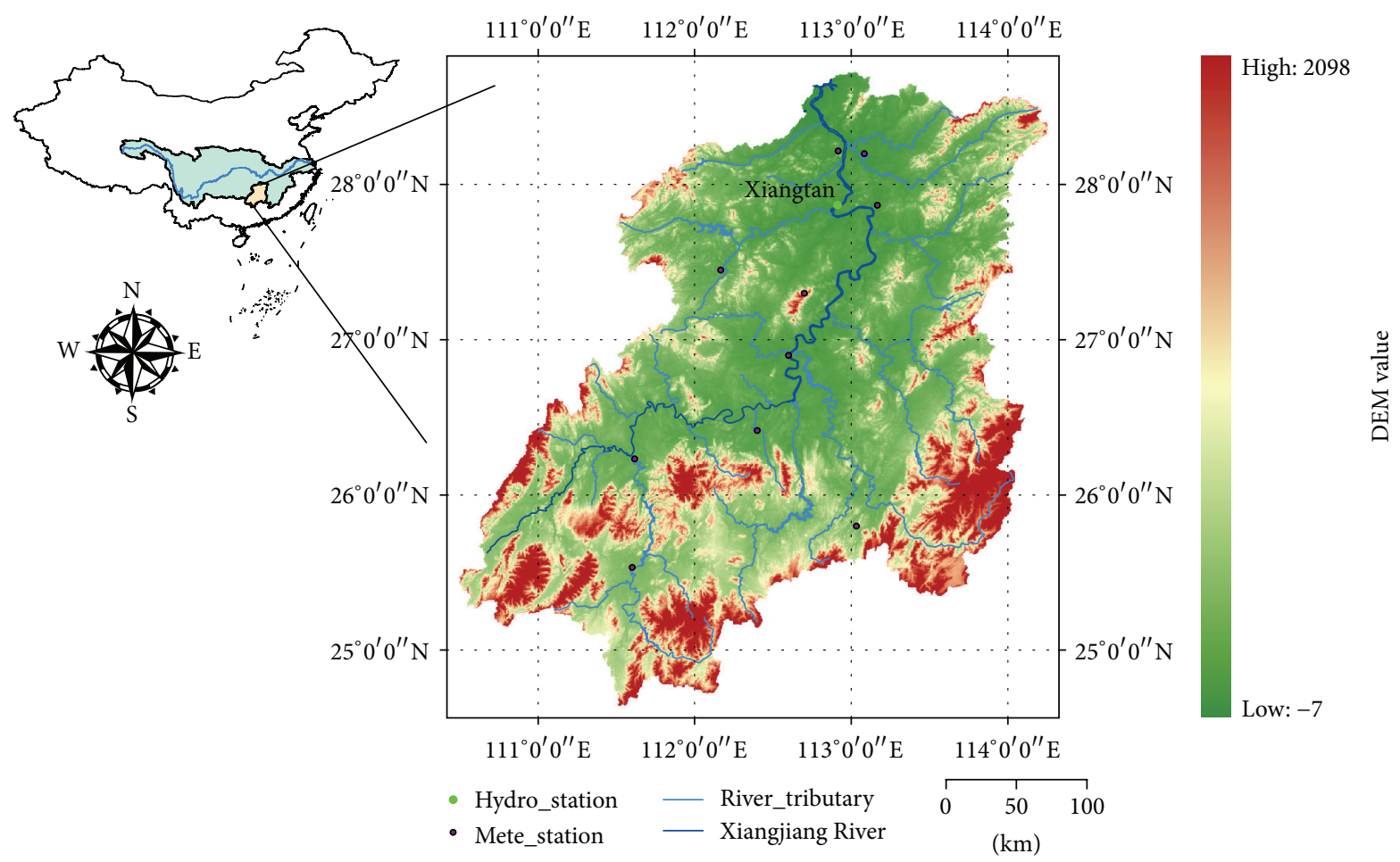

FIGURE 1: Study area and the location of all gauging stations.

have also provided an evidence that the propagation of meteorological drought to groundwater drought decreased the number of drought events and caused a shift in the drought severity distribution [17]. Major related researches have been devoted to how the response of hydrological drought to meteorological drought varied in different timescales and the time-lag of hydrological drought to meteorological drought. Vicente-Serrano and López-Moreno found that surface flows responded to short time scales of meteorological drought (1-4 months) in a mountainous Mediterranean Basin [18]. Tabrizi et al. found that annual time scale of meteorological drought in the upstream of the Doroodzan watershed in Iran was useful in investigating occurrence of streamflow drought in the downstream [19]. Good correlation between annual PDSI, SPI, and Percentage of Rainfall Anomaly was found in ten major basins across China [20]. Four-month timescale of Standardized Precipitation Index (SPI) was proved to be the most suitable indicator when relating with standardized runoff index (SRI) in a typical semiarid inland basin of China [21]. A time-lag of 127 days regarding comparison between streamflow drought and meteorological drought was also found in this area [21]. Similar time lag of 7 months was found in a study conducted in the Awash River basin of Ethiopia [22]. At a small drought-prone basin in Oklahoma of USA, there was a time-lag of 2 months between SRI and SPI in model projection [23].

Considering limited related previous studies on the relationship between hydrological drought and meteorological drought in Asia, the scope of this research lies in the response of streamflow drought to meteorological drought in a humid basin in Southern China. As indicated in a recent study [24],
PET, in the face of climate change, an important component in the hydrologic cycle, should not be ignored in drought monitoring. Different to SPI, PET has been integrated into the Standardized Precipitation Evapotranspiration Index (SPEI) calculation [25], making it more efficient than SPI in drought monitoring at humid and semihumid areas, in which both precipitation and temperature are vital for drought identification.

The main purpose is to test the usefulness of different timescales of SPEI to indicate streamflow drought and how the relation between streamflow drought and meteorological drought behaves in different seasons at humid regions, especially under trend of global warming. The objective is to select the most suitable timescale of SPEI to identify drought in river discharge. Results will be helpful in regional water resources planning and drought management.

\section{Materials and Methods}

2.1. Study Area and Data. Xiangjiang River basin is one of the largest subbasins of Yangtze River Basin. It is located in the southcentral China and most of the basin is within Hunan Province (Figure 1). As a main tributary of the Yangtze River, the Xiangjiang River originates from the mountainous area in the southwest and flows into the Dongting Lake in the northeast. It has a total length of $844 \mathrm{~km}$ and forms a basin of $94,660 \mathrm{~km}^{2}$. The streamflow in this basin is mainly charged by precipitation. Robust linear relationship between monthly mean runoff and monthly precipitation during 1976 and 2005 was found in Figure 2. The elevation in the 


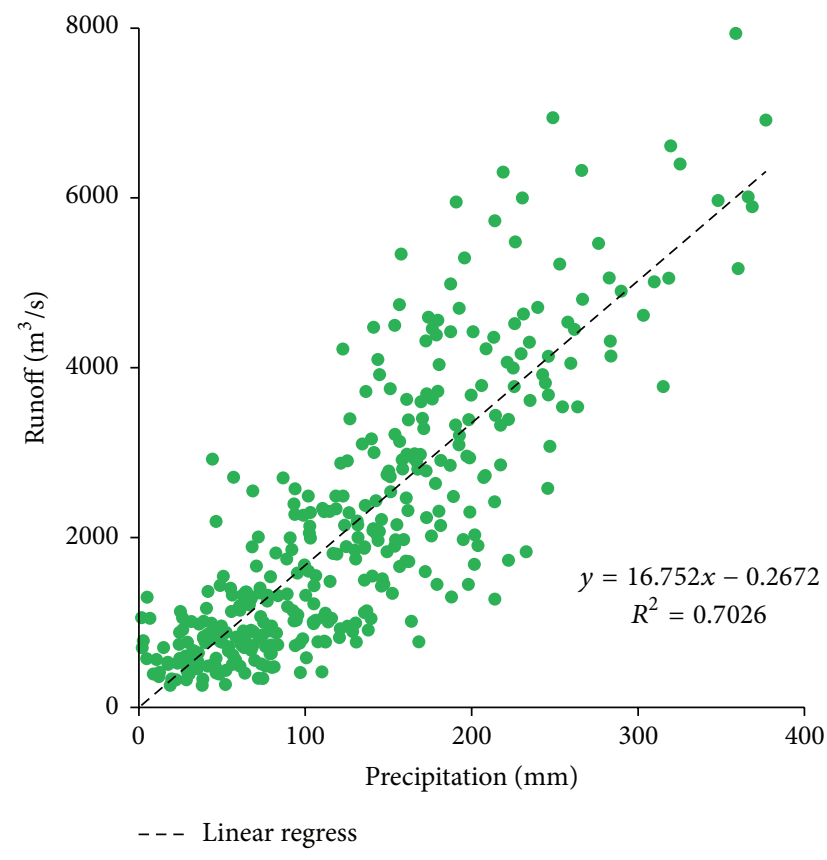

FIGURE 2: Scatter diagram of monthly mean runoff and monthly precipitation during 1976 and 2005.

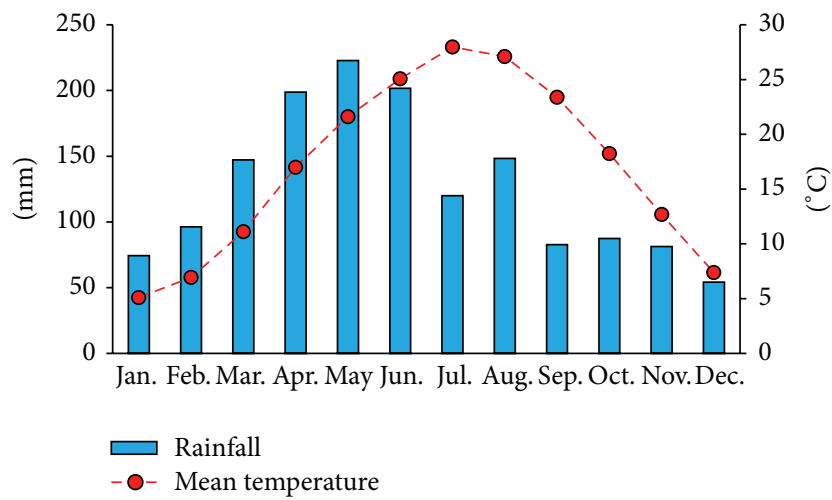

FIGURE 3: Intra-annual variation of monthly average temperature and monthly rainfall during 1976 and 2005.

basin varies from $2098 \mathrm{~m}$ to $0 \mathrm{~m}$, with high mountains in the south and southwest part and flat plains in the north. The basin is characterized as a humid subtropical monsoon climate by averaging monthly temperature and monthly rainfall during 1976 and 2005 (Figure 3). The annual average temperature is about $17.1^{\circ} \mathrm{C}$ and annual average evaporation is around $1200 \mathrm{~mm}$. The annual rainfall ranges from $1170 \mathrm{~mm}$ to $2160 \mathrm{~mm}$ and it is unevenly distributed, making it prone to frequent flood and drought.

There are six meteorological stations in this basin (see black dots in Figure 1). They provide the meteorological information used in this study. The monthly precipitation and mean temperature data covering the period between 1960 and 2014 were provided by the China Meteorological Administration. The daily discharge data were obtained in Xiangtan station (green dot in Figure 1) which is the key hydrological
TABLE 1: Pearson correlation between the average data series and the series of each meteorological station.

\begin{tabular}{lcc}
\hline Station & Precipitation & Temperature \\
\hline Shuangfeng & 0.8731 & 0.9986 \\
Nanyue & 0.8852 & 0.9977 \\
Yongzhou & 0.8962 & 0.9996 \\
Hengyang & 0.8895 & 0.9991 \\
Daoxian & 0.8783 & 0.9989 \\
Chenzhou & 0.8583 & 0.9988 \\
\hline
\end{tabular}

station in the downstream of Xiangjiang River, covering the period between 1976 and 2005. The hydrological data were provided by the Changjiang Water Resources Commission (CWRC) of China. Quality test of meteorological data and discharge data has been conducted before calculation of SPEI and SRI.

To avoid inhomogeneity in the meteorological data, we tested its homogeneity by correlating data series of each meteorological station with the regional average. Table 1 shows the coefficients of Pearson correlation among the monthly precipitation and mean temperature series in each station and the regional average series. Correlation coefficients are very high and significant $(P<0.01)$ in all meteorological stations $(R \geq 0.87)$.

\subsection{Methods}

2.2.1. Evaluation of Meteorological Drought. Meteorological drought events were evaluated based on the newly developed Standardized Precipitation Evapotranspiration Index (SPEI) [25]. The robustness of multiscale characteristics of time for SPEI is similar to the SPI [26]. And it also combines temperature into the model, which is used for calculating potential evapotranspiration (PET). We followed the Thornthwaite approach to calculate PET [27], which proved to be reliable in SPEI calculation [28].

Computation of the SPEI requires long-term monthly meteorological data, which were arranged to appropriate time scales based on different goals, for example, 3 months, 6 months, 9 months, and 12 months. The different timescales (i-month) mean the different time lengths for accumulating precipitation data and averaging temperature data by backtracking. In this study, $i$-month timescale of SPEI was written in SPEIi by short. More detailed calculation procedures could be found in related references [25]. Input monthly precipitation and mean temperature for calculating SPEI were obtained by averaging the data from six meteorological stations, covering the period between 1960 and 2014. In this study, 1- to 12-month timescales of SPEI during 1976 and 2005 were extracted to coincide with the time span of SRI.

The classification of meteorological drought based on SPEI value was given in Table 2 [25]. Four major drought intensities were classified by the different values of SPEI.

2.2.2. Evaluation of Streamflow Drought. The SRI [29] was utilized to identify streamflow drought in this study. It was 
TABLE 2: Classification of drought intensity.

\begin{tabular}{lc}
\hline SPEI/SRI value & Drought intensity \\
\hline$(-1.00,-0.00]$ & Mild drought \\
$(-1.50,-1.00]$ & Moderate drought \\
$(-2.00,-1.50]$ & Severe drought \\
$(-\infty,-2.00]$ & Extreme drought \\
\hline
\end{tabular}

calculated in a manner similar to normal standardization procedure, which was given as

$$
\mathrm{SRI}_{i j}=\frac{\left(R_{i j}-\overline{R_{j}}\right)}{\sigma_{j}},
$$

where $i$ and $j$ were the year and month of the year, respectively $(i=1976,1977, \ldots, 2005 ; j=1,2,3, \ldots, 12) ; \overline{R_{j}}$ and $\sigma_{j}$ were the mean and the standard deviation of $R_{i j}$, respectively. $R_{i j}$ was the natural logarithm of the monthly mean discharge for the given $i$ th year and the $j$ th month. The timescale of SRI was one month.

The classification of streamflow drought based on SRI value was given in Table 2. Four major drought intensities were classified by the different values of SRI.

\subsubsection{The Response Rate of Streamflow Drought to Meteoro-} logical Drought. In this study, we used the response rate $\left(R_{r}\right)$ to indicate the percentage of streamflow drought when meteorological drought occurred. It stands for how streamflow drought responds to different timescales of meteorological drought. The higher $R_{r}$ means this response is more sensitive and vice versa. The specific algorithm for $R_{r}$ was given below:

$$
R_{r}=\frac{n}{m} \times 100 \%,
$$

where $m$ was the occurrence times of meteorological drought (SPEI < 0) during 1976 and 2005 and $n$ was the occurrence times of streamflow drought $(\mathrm{SRI}<0)$ under the condition that SPEI was less than 0 .

\section{Results}

3.1. Temporal Variability of SRI and SPEI. Monthly SRI and different timescales of SPEI in this basin were depicted in Figure 4, covering the period between 1976 and 2005. Four main streamflow drought periods were recognized from SRI series, which were AUG/1977-SEP/1981 (streamflow drought period 1 (SDP1)), JUL/1983-APR/1993 (SDP2), AUG/1998JUN/1999 (SDP3), and JUN/2003-JUN/2004 (SDP4). SDP1 and SDP2 were also characterized by intermittent short wet periods. The other two periods were much shorter, covered by continuous streamflow drought. The most severe streamflow drought occurred in SDP3, which was characterized by extremely low SRI value of consecutive three months (SRI of FMA/1999 <-2).

From views of SPEI at different timescales (Figure 4), evolution of meteorological drought at different timescales can be identified. Higher drought frequency was found at
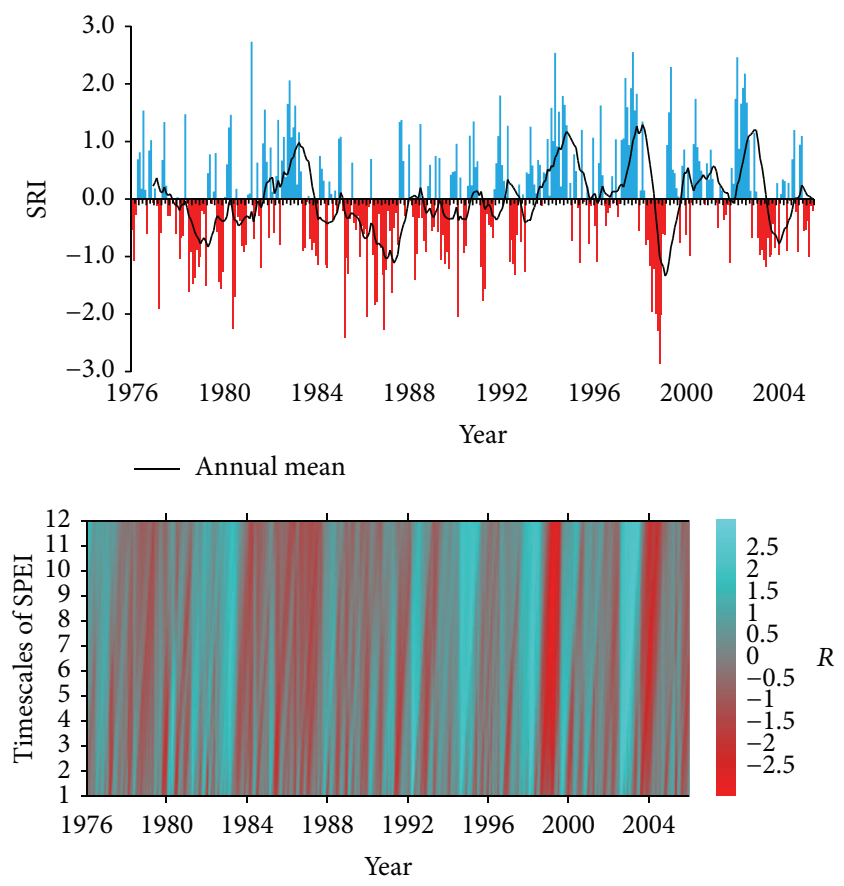

FIgURE 4: Time series of SRI and different timescales of SPEI during 1976 and 2005.

shorter timescales of SPEI. Drought occurrence time of longer timescales lagged that of shorter timescales, which was indicated by that the red vertical stripes (drought events) inclined towards right. In addition, dominant drought spells along with their magnitude and duration can also be clearly seen from Figure 4 . The most severe meteorological drought occurred in 1998-1999. Furthermore, a good correspondence between streamflow drought and meteorological drought can be found from the comparative analysis of SRI and SPEI at different timescales. Two severe or extreme meteorological drought periods mentioned above (1998-1999, 2003-2004) characterized by SPEI at all timescales correspond with SDP3 and SDP4 very well. This result indicated that consecutive severe meteorological drought could lead to severe or consecutive streamflow drought in this basin.

3.2. Relationship between SRI and Different Timescales of SPEI. The Pearson correlation coefficients between SRI and SPEI at different timescales were shown in Figure 5. Correlation coefficients were high and significant at all timescales $(R>$ $0.55, P<0.01)$. There were significant differences with regard to timescales. The maximum correlation coefficient was obtained at 2-month timescale $(R=0.79)$. The correlation decreased gradually along with the increasing timescales. It also indicated that the runoff of Xiangjiang River was mainly charged by rainfall of the current and previous months.

A further analysis of the relationship between SRI and SPEI of different timescales at different months has been conducted. Significant seasonal difference regarding different timescales was found in Figure 6. Higher correlation coefficients were found from October to March at all timescales (mean $R>0.75, P<0.01$ ). The lowest correlation coefficient 


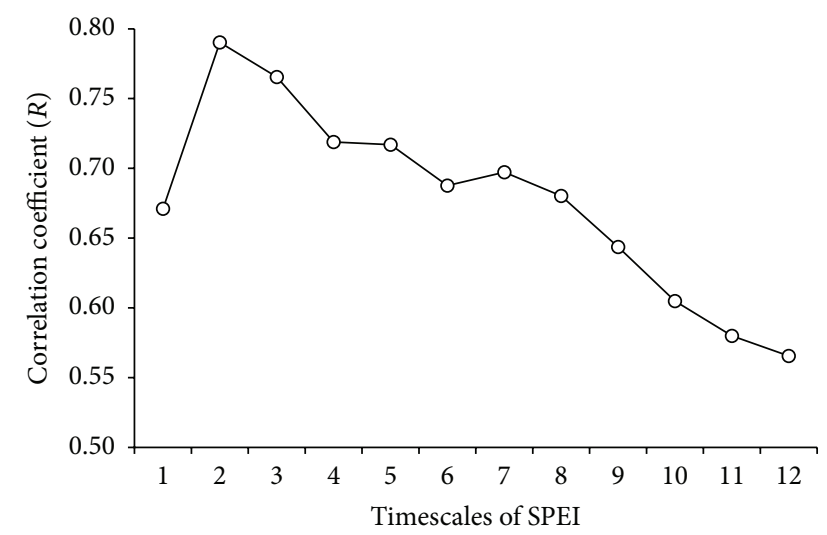

FIGURE 5: Correlation between SRI and the SPEI at different time scales.

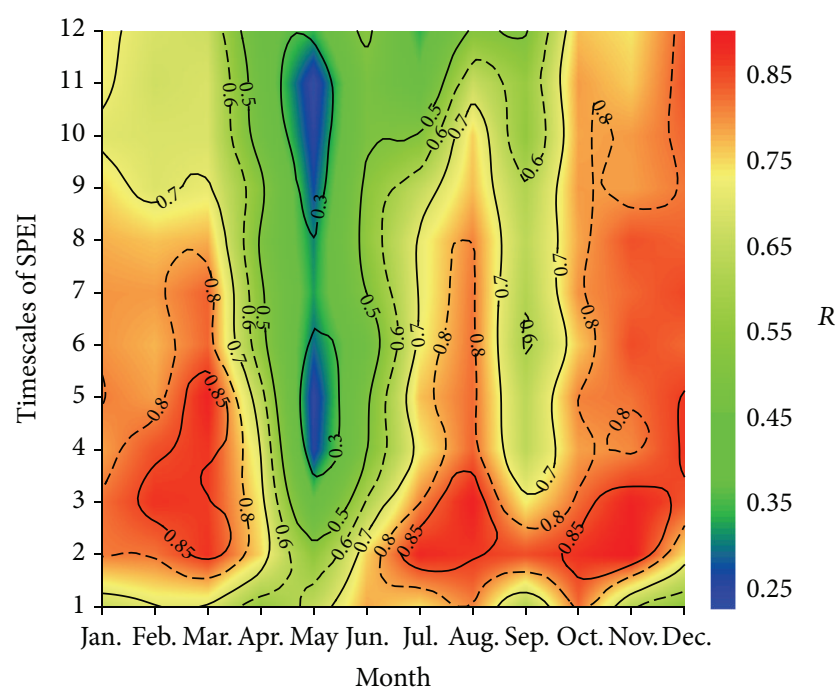

FIGURE 6: Monthly correlation coefficients between SRI and SPEI at different time scales.

was found in May, with most $R$ at different timescales less than 0.5. Regarding timescales, the correlation at 1 month scale was low. It appeared much higher at 2-month scale and decreased gradually when timescale increased. The highest correlation was found at three parts in Figure 6 (the red region with $R$ greater than 0.85 ). The top three high correlation coefficients were obtained in November at 2month scale $(R=0.89)$, August at 3 -month scale $(R=0.88)$, and March at 5 -month scale $(R=0.88)$. Figure 7 showed the SRI series and SPEI series at 2-month timescale in November. It can be clearly found that the fluctuation of SRI accorded with that of SPEI2 very well. Near all the peak and valley of SRI series corresponded to that of SPEI2.

3.3. Response of Streamflow Drought to Meteorological Drought. The response rate $\left(R_{r}\right)$ of streamflow drought to meteorological drought at different timescales was shown in Figure 8. Strong response relationship was found between them. The $R_{r}$ was considerably high at all timescales, with the average $75.4 \%$. At short to medium timescales ( 1 to 8

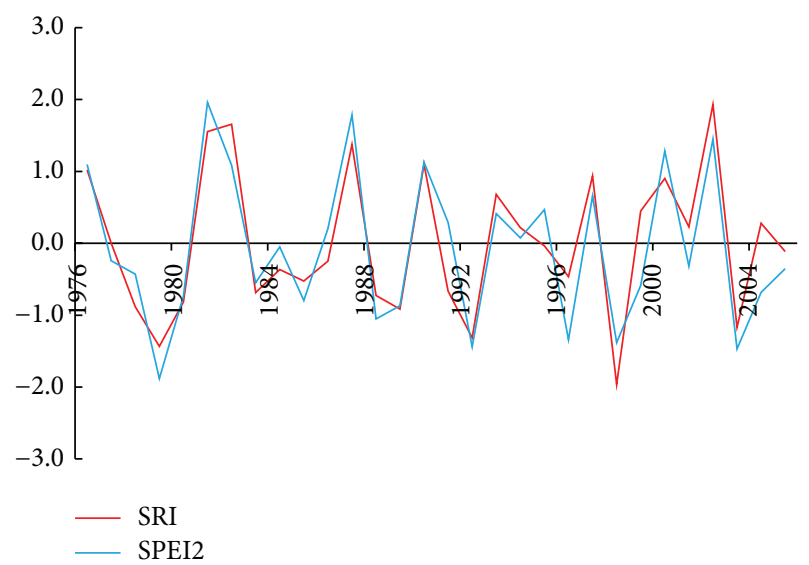

FIGURE 7: SRI and SPEI2 in November during 1976 and 2005.

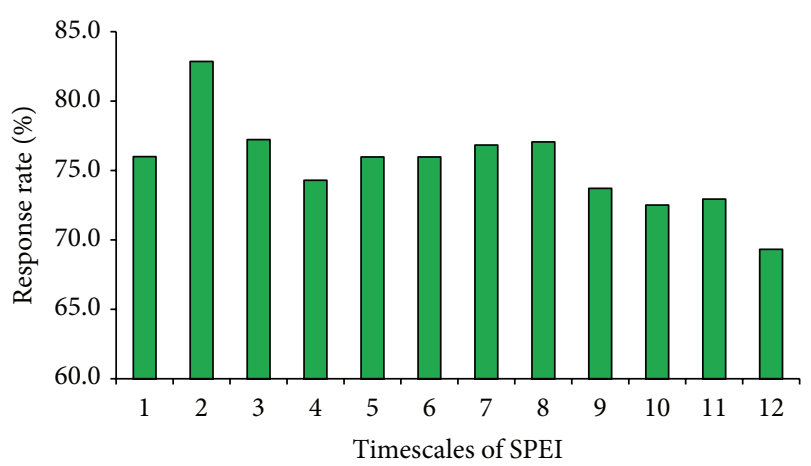

FIGURE 8: Response rate of streamflow drought to meteorological drought at different timescales.

months), the $R_{r}$ remained at about $75 \%$ except that the peak value appeared at 2-month timescale $\left(R_{r}=82.9 \%\right)$. After 8-month scale, $R_{r}$ declined gradually along with the increase of timescale and reached the minimum at 12-month scale $\left(R_{r}=69.3 \%\right)$. Results indicated that streamflow drought in Xiangjiang River basin responded to meteorological drought at 2 -month timescale very well. When meteorological drought occurred (SPEI $<0$ ), the probability of streamflow drought would reach up to $82.9 \%$.

Figure 9 reflected the seasonal difference of response between streamflow drought and meteorological drought. Robust response relation was also found at monthly scale. A majority of response rate was larger than $70 \%$. Moreover, remarkable monthly difference of $R_{r}$ was shown clearly. The sensitivity of streamflow drought to meteorological drought differed in seasons and timescales. Shorter (1-4 months) timescales of SPEI could indicate streamflow drought (SRI < 0 ) better during January and July, whereas medium timescales (5-9 months) of SPEI perform better for indicating streamflow drought from August to December. Higher response rate was found during autumn and winter months (dry seasons). The possible reason is that streamflow responds to rainfall sensitively in dry seasons, while, in wet seasons, this relationship could be affected by other factors such as much more frequent heavy rainfall, stronger evapotranspiration 


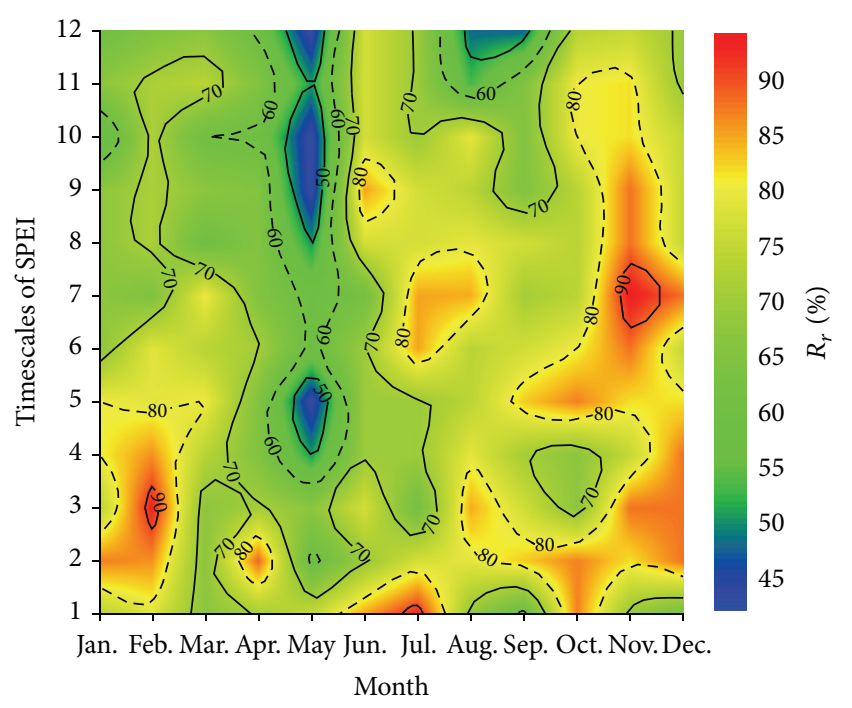

FIgURE 9: Monthly response rate of streamflow drought to meteorological drought at different timescales.

associated with high temperature, and higher water demand such as agricultural irrigation and higher domestic water demands of urban and rural inhabitants. The top three high response rates were obtained in November at 7-month scale $\left(R_{r}=93.8 \%\right)$, February at 3-month scale $\left(R_{r}=92.9 \%\right)$, and July at 1 -month scale $\left(R_{r}=92.3 \%\right)$. The lowest $R_{r}$ appeared in May, with the minimum equal to $41.7 \%$.

\section{Discussion and Conclusion}

In order to understand how streamflow drought responded to meteorological drought in the Xiangjiang River basin, monthly SRI and SPEI of different timescales during 1976 and 2005 were calculated to identify streamflow drought and meteorological drought, respectively. Correlation and response relationship have been investigated. Robust relation between streamflow drought and meteorological drought was found in this basin. The main conclusions were summarized as below:

(1) Relationship between streamflow drought and meteorological drought can be investigated well by the comparative analysis of SRI and SPEI at different timescales. Continuous severe meteorological drought would propagate to severe or consecutive streamflow drought in this basin, whereas intermittent or moderate meteorological drought may lead to separate streamflow drought.

(2) Robust correlation between SRI and SPEI was found. SPEI of 2-month timescale behaved best in correlating with SRI $(R=0.79, P<0.01)$. The longer the timescale of SPEI was, the weaker the correlation was. At seasonal scale, significant difference of correlation was found. Higher correlation coefficients were obtained during dry season (October to March), with the maximum $R$ reaching up to 0.89 , whereas the minimum was found in wet season (April to June).
These findings agreed with the results carried out in the Aragon River basin of the central Spanish Pyrenees [18].

(3) Remarkable results were also found regarding to the response rate of streamflow drought to meteorological drought. The average response rate was considerably high (75.4\%). Maximum $R_{r}$ was obtained at 2month timescale $\left(R_{r}=82.9 \%\right)$. It stated again that SPEI 2 could be used as a good indicator in streamflow drought identification. Besides, $R_{r}$ differed greatly in different seasons. Shorter timescales of meteorological drought could indicate streamflow drought better during winter and spring, whereas streamflow drought in late summer to autumn responded to meteorological drought at medium timescales.

In this study, important relationship between streamflow drought and meteorological drought has been pointed out. This relation would provide scientific support in drought mitigation and regional water resources management. It is also necessary to test the most suitable timescale of meteorological drought index before drought monitoring of different hydrologic variables. Generally, shorter timescales of meteorological drought indices proved to be better when relating to streamflow. Vicente-Serrano and López-Moreno have indicated that $1-4$ months of SPI could relate to the surface flows quite well in a mountainous Mediterranean Basin [18]. A case study conducted in two reservoirs in central Spain has shown that very high correlations $(>0.9)$ were found between hydrological and climatic droughts for timescales between 3 and 5 months, by relating SPI, SPEI to the $z$-standardized inflows [30]. In a plain basin surrounded by high mountains in Greece, higher correlations have also been obtained with the 3-month SPI and 6-month SPI when relating to a standardized runoff index [31]. In another case study conducted in a semiarid basin of China, similar results had indicated that SPI of 4-month timescale correlated with SRI better [21].

In addition, seasonality must also be investigated carefully. Different timescales of meteorological drought indices may behave totally different in various seasons. Streamflow response to climatic droughts may be very different as a function of the river regimes [32]. So, the selection of the most suitable timescale regarding different months before utilizing SPEI to indicates that streamflow drought is of great importance. In this study, SPEI2 was proved to be the most suitable index when relating to SRI generally, whereas SPEI1 and SPEI7 behaved best in July and November, respectively. In central Spain, very high correlations were found between hydrological and climatic droughts from January to March for timescales between 3 and 5 months. In contrast, correlations during summer months were very low at the shortest timescales [30]. However, in some high-latitude Asian basins that drain to the Arctic Ocean, correlations between SPEI and SSI were much higher in July than in January [32].

The noticeable timescale issue and seasonality may depend on the basin characteristics, elevation, terrain, climate zone, vegetation cover, and water resources regulation. How do these factors affect the sensitivity of streamflow 
drought to meteorological drought? Maybe it can be explained by comparison among similar basins in the future research. Besides, interannual variability of the propagation procedure under global warming could be obtained if there is long-term hydrologic and climatic data. Furthermore, how meteorological drought propagate through the hydrologic system quantitatively and the time lag between meteorological drought and other types of drought are also interesting issues that should be addressed in a future study.

\section{Conflict of Interests}

The authors declare that there is no conflict of interests regarding the publication of this paper.

\section{Acknowledgments}

This work is supported by National Natural Science Foundation of China (Grant no. 41301586) and China Postdoctoral Science Foundation (Grants nos. 2013M540599 and 2014T70731).

\section{References}

[1] D. A. Wilhite, "Drought as a natural hazard: concepts and definitions," in Drought: A Global Assessment, D. A. Wilhite and O. Vanyarkho, Eds., Routledge, New York, NY, USA, 2000.

[2] FEMA, National Mitigation Strategy: Partnerships for Building Safer Communities, Federal Emergency Management Agency, Washington, DC, USA, 1995.

[3] S. M. Vicente-Serrano, C. Gouveia, J. J. Camarero et al., "Response of vegetation to drought time-scales across global land biomes," Proceedings of the National Academy of Sciences of the United States of America, vol. 110, no. 1, pp. 52-57, 2013.

[4] Z. T. Wu, J. J. Wu, B. He et al., "Drought offset ecological restoration program-induced increase in vegetation activity in the Beijing-Tianjin Sand Source Region, China," Environmental Science and Technology, vol. 48, no. 20, pp. 12108-12117, 2014.

[5] R. B. Austin, C. Cantero-Martínez, J. L. Arrúe, E. Playán, and P. Cano-Marcellán, "Yield-rainfall relationships in cereal cropping systems in the Ebro river valley of Spain," European Journal of Agronomy, vol. 8, no. 3-4, pp. 239-248, 1998.

[6] Q. F. Wang, J. J. Wu, T. J. Lei et al., “Temporal-spatial characteristics of severe drought events and their impact on agriculture on a global scale," Quaternary International, vol. 349, pp. 10-21, 2014.

[7] A. T. De Gaetano, "A temporal comparison of drought impacts and responses in the New York City metropolitan area," Climatic Change, vol. 42, no. 3, pp. 539-560, 1999.

[8] S. E. Nicholson, C. J. Tucker, and M. B. Ba, "Desertification, drought, and surface vegetation: an example from the west African Sahel," Bulletin of the American Meteorological Society, vol. 79, no. 5, pp. 815-829, 1998.

[9] J. G. Pausas, "Changes in fire and climate in the eastern Iberian Peninsula (Mediterranean basin)," Climatic Change, vol. 63, no. 3, pp. 337-350, 2004.

[10] A. Dai, "Drought under global warming: a review," Wiley Interdisciplinary Reviews: Climate Change, vol. 2, no. 1, pp. 4565, 2011.
[11] A. G. Dai, "Increasing drought under global warming in observations and models," Nature Climate Change, vol. 3, no. 1, pp. 52-58, 2013.

[12] D. A. Wilhite and M. H. Glantz, "Understanding the drought phenomenon: the role of definitions," Water International, vol. 10, no. 3, pp. 111-120, 1985.

[13] K. C. Mo, "Model-based drought indices over the United States," Journal of Hydrometeorology, vol. 9, no. 6, pp. 1212-1230, 2008.

[14] V. Mishra and K. A. Cherkauer, "Retrospective droughts in the crop growing season: implications to corn and soybean yield in the Midwestern United States," Agricultural and Forest Meteorology, vol. 150, no. 7-8, pp. 1030-1045, 2010.

[15] V. Mishra, K. A. Cherkauer, and S. Shukla, "Assessment of drought due to historic climate variability and projected future climate change in the midwestern United States," Journal of Hydrometeorology, vol. 11, no. 1, pp. 46-68, 2010.

[16] H. Hisdal and L. M. Tallaksen, "Estimation of regional meteorological and hydrological drought characteristics: a case study for Denmark," Journal of Hydrology, vol. 281, no. 3, pp. 230-247, 2003.

[17] E. Peters, H. A. J. Van Lanen, P. J. J. F. Torfs, and G. Bier, "Drought in groundwater: drought distribution and performance indicators," Journal of Hydrology, vol. 306, no. 1-4, pp. 302-317, 2005.

[18] S. M. Vicente-Serrano and J. I. López-Moreno, "Hydrological response to different time scales of climatological drought: an evaluation of the Standardized Precipitation Index in a mountainous Mediterranean basin," Hydrology and Earth System Sciences, vol. 9, no. 5, pp. 523-533, 2005.

[19] A. A. Tabrizi, D. Khalili, A. A. Kamgar-Haghighi, and S. ZandParsa, "Utilization of time-based meteorological droughts to investigate occurrence of streamflow droughts," Water Resources Management, vol. 24, no. 15, pp. 4287-4306, 2010.

[20] J. Q. Zhai, B. D. Su, V. Krysanova, T. Vetter, C. Gao, and T. Jiang, "Spatial variation and trends in PDSI and SPI indices and their relation to streamflow in 10 large regions of china," Journal of Climate, vol. 23, no. 3, pp. 649-663, 2010.

[21] L. Zhao, A. F. Lyu, J. J. Wu et al., "Impact of meteorological drought on streamflow drought in Jinghe River Basin of China," Chinese Geographical Science, vol. 24, no. 6, pp. 694-705, 2014.

[22] D. C. Edossa, M. S. Babel, and A. D. Gupta, "Drought analysis in the Awash river basin, Ethiopia," Water Resources Management, vol. 24, no. 7, pp. 1441-1460, 2010.

[23] L. Liu, Y. Hong, and C. N. Bednarczyk, "Hydro-climatological drought analyses and projection using meteorological and hydrological drought indices: a case study in Blue River Basin, Oklahoma," in Proceedings of the 36th NOAA Annual Climate Diagnostics and Prediction Workshop, Fort Worth, Tex, USA, October 2011.

[24] M. A. A. Zarch, B. Sivakumar, and A. Sharma, "Droughts in a warming climate: a global assessment of Standardized precipitation index (SPI) and Reconnaissance drought index (RDI)," Journal of Hydrology, vol. 526, pp. 183-195, 2015.

[25] S. M. Vicente-Serrano, S. Beguería, and J. I. López-Moreno, "A multiscalar drought index sensitive to global warming: the standardized precipitation evapotranspiration index," Journal of Climate, vol. 23, no. 7, pp. 1696-1718, 2010.

[26] T. B. McKee, N. J. Doesken, and J. Kleist, "The relationship of drought frequency and duration to time scales," in Proceedings of the 8th Conference on Applied Climatology, pp. 179-184, Anaheim, Calif, USA, January 1993. 
[27] C. W. Thornthwaite, "An approach toward a rational classification of climate," Geographical Review, vol. 38, no. 1, pp. 55-94, 1948.

[28] M. X. Yu, Q. Li, M. J. Hayes, M. D. Svoboda, and R. R. Heim, “Are droughts becoming more frequent or severe in China based on the standardized precipitation evapotranspiration index: 19512010?" International Journal of Climatology, vol. 34, no. 3, pp. 545-558, 2014.

[29] I. Nalbantis and G. Tsakiris, "Assessment of hydrological drought revisited," Water Resources Management, vol. 23, no. 5, pp. 881-897, 2009.

[30] J. Lorenzo-Lacruz, S. M. Vicente-Serrano, J. I. López-Moreno, S. Beguería, J. M. García-Ruiz, and J. M. Cuadrat, "The impact of droughts and water management on various hydrological systems in the headwaters of the Tagus River (central Spain)," Journal of Hydrology, vol. 386, no. 1-4, pp. 13-26, 2010.

[31] L. Vasiliades, A. Loukas, and N. Liberis, "A water balance derived drought index for Pinios River Basin, Greece," Water Resources Management, vol. 25, no. 4, pp. 1087-1101, 2011.

[32] S. M. Vicente-Serrano, S. Beguería, J. Lorenzo-Lacruz et al., "Performance of drought indices for ecological, agricultural, and hydrological applications," Earth Interactions, vol. 16, no. 10, pp. 1-27, 2012. 

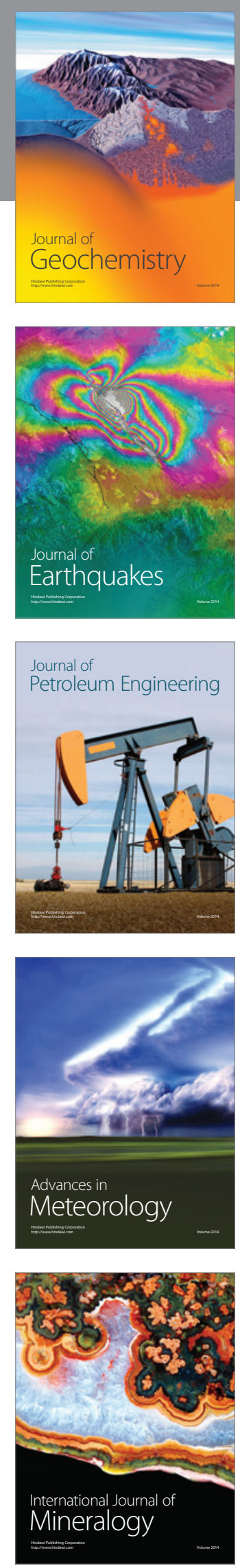
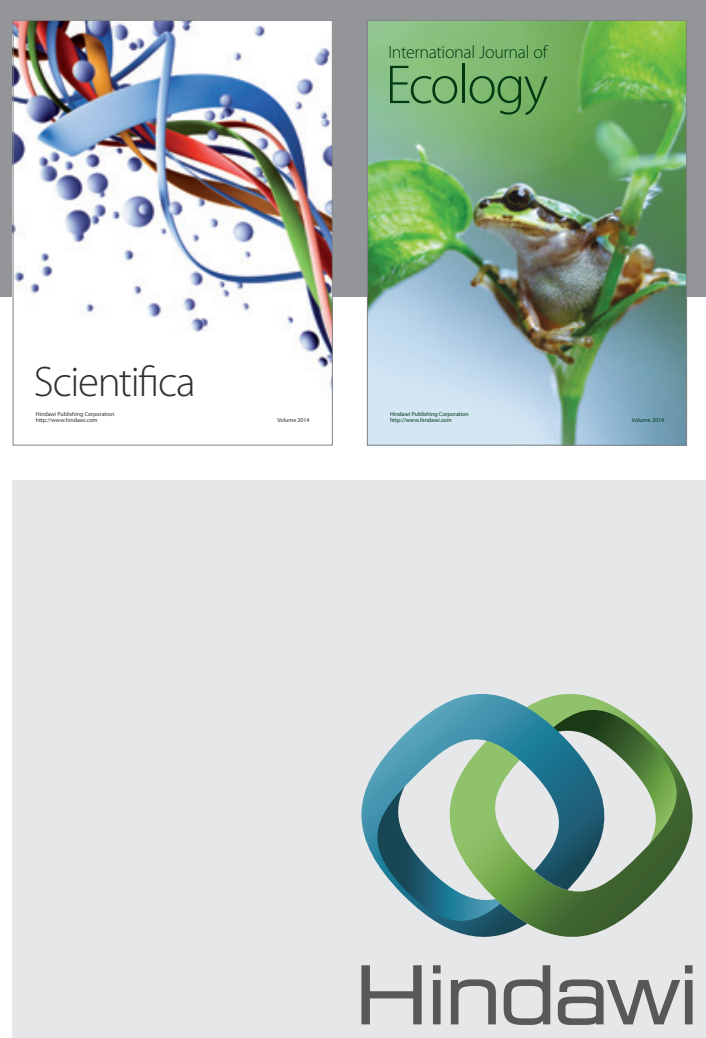

Submit your manuscripts at

http://www.hindawi.com
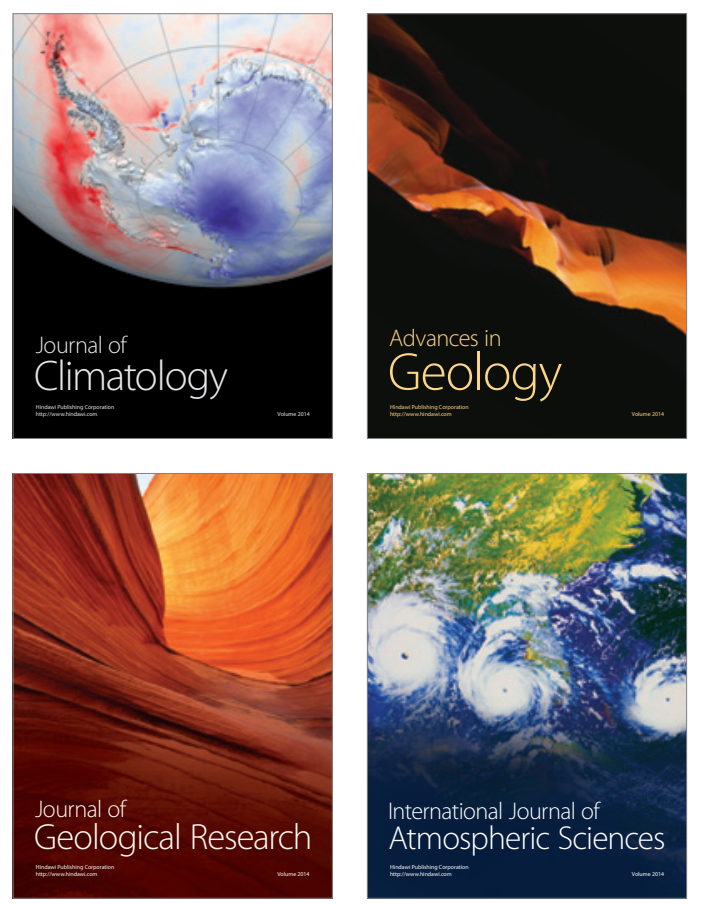

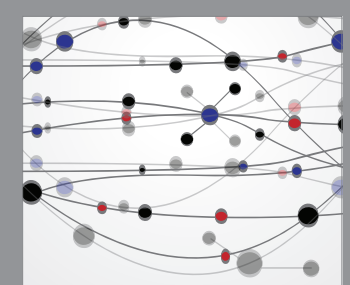

The Scientific

\section{World Journal}
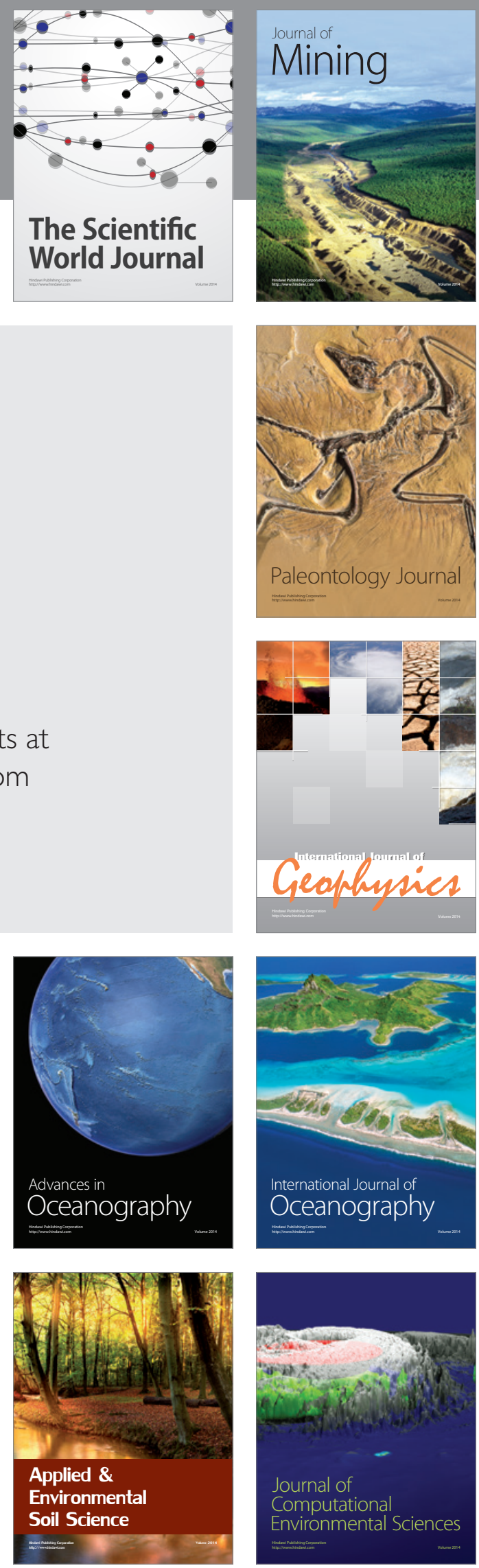